\title{
UNDERSTANDING PUBERTY AND ITS MEASUREMENT: \\ IDEAS FOR RESEARCH IN A NEW GENERATION
}

Jane Mendle, Ph.D. ${ }^{1}$, Adriene Beltz, Ph.D. ${ }^{2}$, Rona Carter, Ph.D. ${ }^{2}$, \& Lorah Dorn, Ph.D. ${ }^{3}$

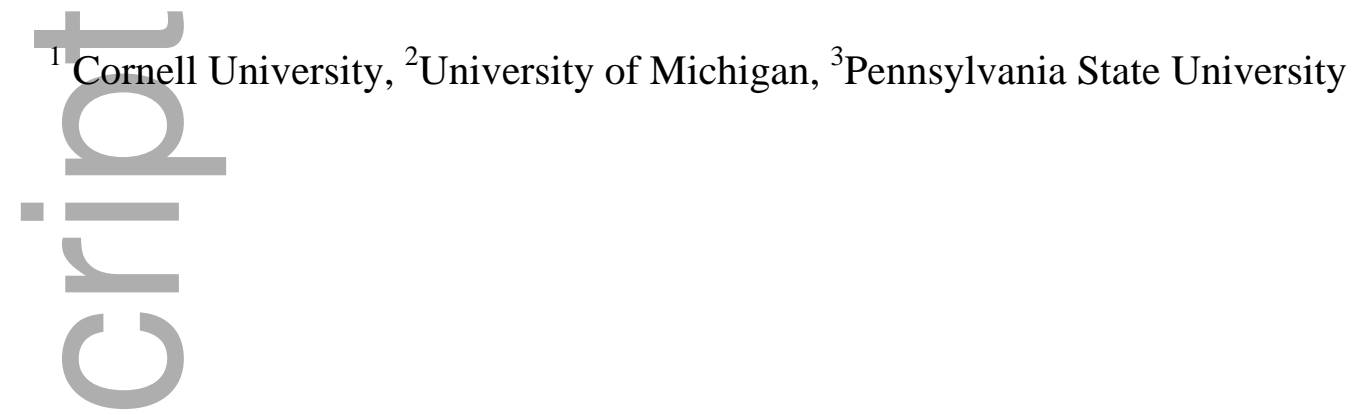

Corresponding author:

Jane Mendle

Department of Human Development

Cornell University

Ithaca, NY 14853

jem482@cornell.edu
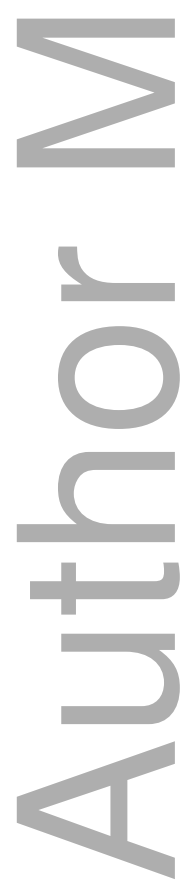

This is the author manuscript accepted for publication and has undergone full peer review but has not been through the copyediting, typesetting, pagination and proofreading process, which may lead to differences between this version and the Version of Record. Please cite this article as doi: $\underline{10.1111 / \text { jora. } 12371}$

This article is protected by copyright. All rights reserved 


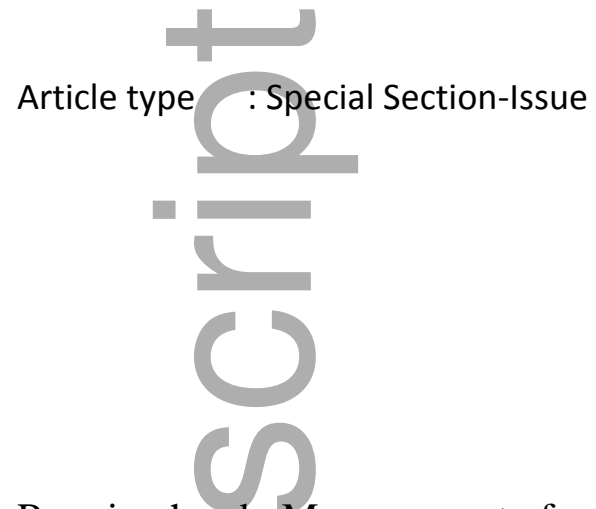

Running head: Measurement of puberty for psychological research

UNDERSTANDING PUBERTY AND ITS MEASUREMENT: IDEAS FOR RESEARCH IN A NEW GENERATION

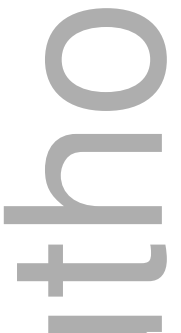

The measurement of puberty is an intricate and precise task, requiring a match between participants' developmental age and appropriate techniques to identify and capture variations in maturation. Much of the foundational work on puberty and its psychosocial correlates was conducted several decades ago. In this article, we review the biological foundation of puberty; the operationalization of puberty in statistical analyses; and strategies for considering diversity and social context in research to help researchers align measurement with meaningful conceptual questions. These three areas are particularly important, given new statistical techniques, greater 
awareness of individual variations in development, and key differences between past cohorts and youth coming of age today.

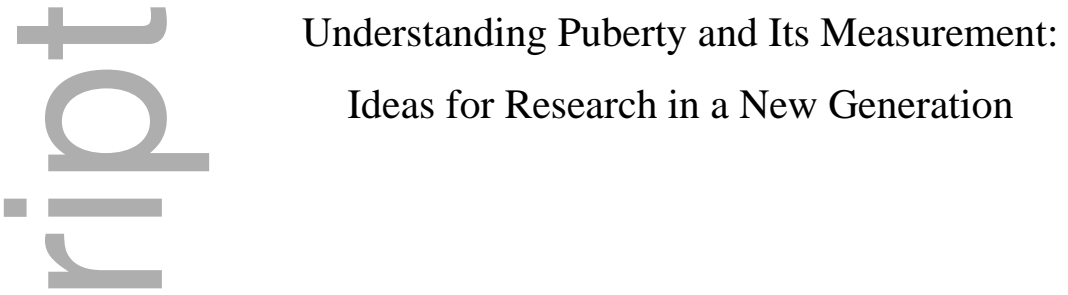

Puberty is a complex, integrative, and coordinated transition, marked by change in body, brain, behavior, cognition, and emotion. The past decade has seen a renaissance in scientific inquiry dedicated to puberty, with scholars today leveraging cutting edge statistical and imaging techniques, and drawing on nearly five decades of scientific scholarship to understand this pivotal transition. While this resurgence is an exciting one, it is simultaneously marked by critical challenges. These include both long-standing methodological and measurement dilemmas, rooted in the inherent intricacy of the pubertal transition, as well as new and unexpected questions that have emerged in concert with recent research findings across disciplines and levels of analysis.

The current paper explores the principal issues underlying measurement, conceptualization, and operationalization of puberty in psychological research. Our central goal is to provide a thorough foundation in the basics of pubertal maturation, to ensure scholars particularly those who may be less familiar with the topic - are prepared to conduct empirically sound research that makes a strong contribution to the field. We additionally discuss needed revisions to the scientific approach to studying puberty. Much of the foundational work on the psychological salience of puberty was conducted in the 1970s-1990s (e.g., Petersen, TobinRichards, \& Boxer, 1983; Brooks-Gunn, Petersen, \& Eichorn, 1985; Simmons \& Blyth, 1987; Susman et al., 1985). Youth today differ from those cohorts in the timing, onset, and duration of maturation; the dialogue surrounding sexual maturation; the social awareness of human diversity; and the demographic make-up and economic circumstances of the country in which they live. As scholars, we must ensure that our research questions, methods, and approaches have been adapted to address these changes. Quite simply, we cannot assume that the methods and theories developed several decades ago will necessarily be applicable or appropriate for today's youth. 
Notably, there are already several exceptional papers detailing various ways to measure puberty across different scientific disciplines (e.g., Bernbaum, Beltz, \& Corley, 2015; Dorn, Dahl, Woodward, \& Biro, 2006; Dorn \& Biro, 2011). Those papers collectively emphasize the need to match the type of measurement with the research question. We refer readers interested in specific measurement techniques to those works. Our focus in this paper is to offer new ideas, perspectives for research, and methodological principles to help align the measurement of puberty with meaningful theoretical questions. We especially highlight three main areas: the biological foundation of puberty; the operationalization of puberty in statistical analyses; and strategies for considering diversity and social context in research.

\section{Understanding the Basics of Pubertal Development}

Puberty is the gateway to adult reproductive competence, encompassing a suite of changes resulting from maturation of the brain and neuroendocrine function (Lee \& Styne, 2013). These neural changes trigger numerous observable physical changes, including changes in height and the development of primary and secondary sexual characteristics in both males and females. As children develop physically, they also face changes in their social roles and relationships, in how they think about themselves and others, and in how they process and respond to the world around them. Here, we briefly review the biological foundation of puberty. For additional information, we encourage the reader to refer to the papers in this issue on new research in puberty and structural and functional brain remodeling in puberty and adolescence (citations blinded for review).

\section{Biological Foundation of Puberty}

Puberty comprises two distinct but overlapping processes, adrenarche and gonadarche. Adrenarche, or "awakening of the adrenal glands," occurs at approximately age 6 to 8 years (e,g, Byrne et al., 2017; Lee \& Styne, 2013; Styne \& Grumbach, 2016). Adrenarche is marked by a dramatic rise in three adrenal steroid hormones: androstenedione (delta-4A), dehydroepiandrosterone (DHEA) and its sulfate (DHEAS). These hormones continue to increase into the third decade of life before they plateau, and eventually decline. Changes associated with adrenarche include increased skin oil and acne, skeletal maturation, and pubic hair growth.

Gonadarche follows adrenarche approximately one to two years later. The hypothalamic pituitary gonadal (HPG) axis refers to the coordinated endocrine function of the hypothalamus, pituitary gland, and gonads. The HPG axis is active in the early postnatal period (and up to age 
two in girls), but enters a quiescent period until puberty. At puberty, the gonadotropin-releasing hormone $(\mathrm{GnRH})$ pulse generator in the hypothalamus is reactivated (Bordini \& Rosenfield, 2011; Rey et al., 2016; Styne \& Grumbach, 2016). GnRH stimulates the anterior pituitary gland to create a pulsatile secretion of both luteinizing hormone $(\mathrm{LH})$ and follicle stimulating hormone (FSH) followed by the production of sex steroids from the gonads. In females, increased estrogen facilitates the development of secondary sexual characteristics, such as breast and hip growth, and eventually menstruation. In boys, increased testosterone results in testicular development, growth of facial hair, and changes in voice.

Gonadarche is a gradual and somewhat lengthy process, roughly four to five years in duration. It begins approximately one to one and half years later in boys than in girls. In girls, the first change resulting from the HPG axis typically reported is thelarche, or the onset of breast development, while for boys, the first change is typically testicular growth (Lee \& Styne, 2013; Styne \& Grumbach, 2016). Menarche, or a girl's first menstrual cycle, is a relatively late gonadal event, occurring between 1.5 and 3 years after breast development begins. It may take an additional three to five years post-menarche for menstrual cycles to stabilize and become regular.

In addition to adrenarche and gonadarche, the growth axis is also activated in puberty. Just prior to pubertal onset, growth hormone $(\mathrm{GH})$ and rate of growth decrease, followed by an increase at puberty when the growth axis is stimulated by rising sex steroids and GH is secreted in a pulsatile fashion (Styne \& Grumbach, 2016). As puberty progresses, pulses become significantly higher in amplitude and duration (Veldhuis, Roemmich, \& Rogol, 2000). Insulinlike growth factor (IGF-1) also increases and is correlated with secondary sexual characteristics as well as with concentrations of sex steroids (Korth-Schutz, Levin, \& New, 1976; Sizonenko \& Paunier, 1975). Since the majority of linear growth is complete in girls at menarche, GH is "turned down" to prepubertal levels at the end of puberty (Albertsson-Wikland et al, 1994). For boys, height velocity increases approximately 1-2 years later than girls, and seems to peak about three-quarters of the way through the pubertal transition (Abbassi, 1998).

Timing of pubertal milestones can vary substantially across populations, demographic groups, and studies. In the United States, recent estimates suggest that boys show early signs of gonadarche on average at age ten, with Latino and African American boys maturing approximately six months ahead of European American boys (Herman-Giddens et al., 2012). In 
girls, early signs of gonadarche are evident in most people at around age nine to ten years (Biro, et al., 2013; Cabrera, Bright, Frane, Blethen, \& Lee, 2014; Susman et al., 2010), with roughly $18 \%$ of European American and $40 \%$ of African American girls showing signs of breast development at age eight (Biro et al., 2010). Importantly, these ages are earlier than documented in previous generations, and convincingly suggest that puberty's onset has shifted to a younger chronological age (Lee \& Styne, 2013). This earlier onset is evident in both girls and boys from Europe (Aksglaede et al., 2008, 2009) as well as in the United States (Euling et al., 2008; Biro et al., 2013), and observed in the age of growth spurt as well as in gonadal indicators (Aksglaede et al., 2008). Because the age at which puberty ends has not shifted as dramatically as the age at which it starts (reviewed in Lee \& Styne, 2013; Mendle, 2014), youth may be spending a longer period of time in the pubertal transition than youth in previous generations.

For researchers, these secular changes in pubertal development pose practical issues for research methods. Pubertal youth may cognitively and behaviorally resemble children more than adolescents and they may have reading levels consistent with their chronological age. There may be a need to update assumptions about the psychological experience of puberty, self-report psychological measures, and target population age to best capture and represent children's experiences. In addition, being sensitive and well-versed in developmental norms regarding puberty will enhance the quality and validity of scientific research. For example, studies that ask participants to self-report development at an age during which youth are not typically experiencing pubertal change (i.e., girls who are too old, such as over fourteen years) would miss much of the pubertal process; any effects would likely be driven by a small number of outliers with an unusually late maturation. Likewise, knowing that girls tend to enter gonadarche earlier than boys is relevant for determining enrollment criteria in a study. Because different psychological and social processes may be evident earlier versus later in puberty, enrolling girls who are 1-2 years younger than boys will capture comparable stages in the pubertal process for both sexes.

Common Measures of Puberty

Where a child is in the process of puberty is commonly referred to as pubertal status. Beginning in the 1960s, physicians and other medical personnel began to use a system known as Tanner Stages to categorize pubertal status based on breast and pubic hair development in girls 
and testicular and pubic hair development in boys (Marshall \& Tanner, 1969, 1970; Tanner, 1962). Tanner Stage 1 indicates no visible signs of development in these domains, while Tanner Stage 5 indicates full physical maturation. Assessments of Tanner Stages can be completed by nurses or medical personnel trained in a physical exam of this nature, or by parents or youth using photographs or pictorial images for guidance to obtain parent- or self-perception of stage. Researchers, particularly those without access to partnerships at medical facilities, have also frequently used the Pubertal Development Scale (Petersen, Crockett, Richards, \& Boxer, 1988; Petersen et al., 1983), comprising five items for each sex assessing perceived changes in height, body hair, and skin (for both sexes), age at menstrual onset and breast development (for girls), and facial hair and voice deepening (for boys). Less commonly, studies have also used hormonal assays to reflect aspects of puberty or asked youth to report their level of development relative to peers (see below, also Berenbaum et al., 2015; Dorn et al., 2006; Dorn \& Biro, 2011; Harden, Kretsch, Moore, \& Mendle, 2014; Huang et al., 2012; Shirtcliff, Dahl, \& Pollack, 2009 for strengths and merits of each measurement type).

\section{How to Capture Individual Differences in Pubertal Development: Merging Measurement and Methods}

Puberty is a highly individualized process. Youth differ from each other not only in their psychological responses to maturation, but also in the age at which they physically mature (known as pubertal timing); the pace of their maturation (commonly called pubertal tempo), and the alignment of their different pubertal changes with each other (pubertal synchrony). It should be noted that these individual differences often rely, conceptually and statistically, on accurate assessments and measurement of pubertal status. Therefore, research that focuses on comparisons of pubertal status asks "what are typical psychological changes that occur as children enter and progress through puberty?" whereas research that focuses on pubertal timing, tempo, or synchrony asks "do individual differences in maturation contribute to different psychological experiences at puberty (or different experiences that may persist or even emerge in adulthood)?"

A recurrent question in puberty research is how to capture these significant sources of variability in individual maturation. This question both contrasts and complements questions about normative development. Historically, pubertal timing, or when a youth develops with respect to same-age, same-sex peers, has been the most well-documented, well-researched 
individual difference in pubertal development (Susman \& Dorn, 2009). However, the past five years have seen a growing interest in studying other individual differences at puberty (e.g., Mendle, 2014). This work has been fostered by, among other things, statistical advances that allow researchers to transform longitudinal puberty assessments into increasingly nuanced representations of how development unfolds for an individual over time. This section will cover the measurement and operationalization of the three main sources of individual variation at puberty: timing, tempo, and synchrony. The strengths and weaknesses of common and recent measures will be noted, particularly when used in relation to psychological antecedents and outcomes.

Pubertal Timing

Pubertal timing is a key psychological construct. It has been related to adolescent changes in brain structure and function, cognition, early life adversities, and internalizing and externalizing behavior, including clinical diagnoses that persist into adulthood (Beltz \& Berenbaum, 2013; Graber, 2013; Herting \& Sowell, 2017; Mendle, Ryan, \& McKone, 2016; Negriff \& Susman, 2011; Ryan, Mendle, \& Markowitz, 2015). Pubertal timing can be assessed in two ways. First, individuals can report when they experienced particular pubertal milestones (such as menarche). Second, timing can be statistically estimated by comparing assessments of physical development - such as Tanner Stage or scores on the PDS -- across youth of the same chronological age. Either way, a complete understanding of pubertal timing first requires knowledge of the different measures of puberty, which vary according to whether they are (1) objective, subjective, or perceived, (2) concurrent or retrospective, and (3) cross-sectional or longitudinal. As this information has been discussed extensively in other sources (e.g., Berenbaum et al., 2015; Dorn \& Biro, 2011; Dorn et al., 2006), it is only reviewed in brief here. Objective measures of puberty capture biological changes related to a specific pubertal process (i.e., gonadarche, adrenarche, or growth) and are typically assessed by a health provider or research professional. Examples include hormone assessments, measures of height extracted from medical charts, and clinician Tanner staging of gonadal or adrenal indicators. Subjective measures capture similar information, but they are typically self- or parent-reported, such as selfreported axillary hair on the PDS. (Unfortunately, age at spermarche is not a particularly good measure for boys, as discussed in Dorn et al., 2006). Some subjective measures also target perceived pubertal timing, usually assessed via self-report. Rather than asking adolescents 
directly about specific physical changes, these measures ask adolescents how their development compares to that of their same-age peers. Is it earlier, about the same, or later? Because these questions are not anchored in particular physical milestones, assessments of perceived development capture a confluence of biological, social, and cognitive changes related to puberty (Moore, Harden, \& Mendle, 2014), rather than pure biological change.

There is an implicit assumption that objective measures are "better" than subjective or perceived measures, and that micro-level biological indicators (e.g., hormones) are "better" than macro-level ones (e.g., breast growth), but neither statement is necessarily true. Physician-rated Tanner Stages remain the "gold standard" for assessing pubertal development (Dorn \& Biro, 2011; Dorn et al., 2006) in part because they go beyond hormone levels to reflect endophenotypes of hormone effects on the brain and body. It should also be noted that youth are notoriously poor at reporting some biological indicators (e.g., skin changes; Dorn et al., 2006) but can be more accurate at others (e.g., menarche; Casey et al., 1991). Even self-reported PDS ratings and perceived timing reports can be valid and reliable (Beltz, Corley, Bricker, Wadsworth, \& Berenbaum, 2014; Dubas, Graber, \& Petersen, 1991; Graber, Lewinsohn, Seeley, \& Brooks-Gunn, 1997). Longitudinal studies of perceived pubertal timing indicate stability and continuity of perceived development across adolescence; youth who perceive themselves as early developers tend to report this across multiple time points during adolescence (Cance, Ennett, Morgan-Lopez, \& Foshee, 2012; Dubas, Graber, \& Petersen, 1991). The bottom line is that different measures are suitable for different research questions. If the research question is about masculinization of neural reward circuitry in adolescence, then testosterone assessments may be ideal. If the question is about changes in adult social roles that began at puberty, then perceived assessment of maturation could be optimal.

Pubertal timing can be gauged either concurrently or retrospectively. Concurrent measures assess ongoing pubertal development in youth who are currently navigating puberty, while retrospective measures assess development after puberty is complete, typically in late adolescence or early adulthood. Again, there is an implicit bias within the field towards concurrent measures, as youth are currently in the midst of pubertal change. However, retrospective measures also have advantages, namely allowing researchers to test complex longitudinal hypotheses about the role of puberty across time and to assess the longevity of pubertal timing effects. In addition, although objective retrospective measures like age at 
menarche have been and continue to be widely-used, perceived retrospective measures are also seeing increased use (e.g., Beltz \& Berenbaum, 2013; Carter \& Williams, 2016; Moore, McKone, \& Mendle, 2016; Zehr et al., 2007). Despite concerns about the accuracy of retrospective reports, it has been suggested that the social comparison inherent in perceived measures likely enhances the salience and memory of pubertal events (Beltz \& Berenbaum, 2013). This may partially explain why perceptions of pubertal timing tend to be strong predictors of psychological outcomes even many years post-pubertally (e.g., Graber, 2004; Moore et al., 2016).

Calculating Pubertal Timing from Cross-Sectional and Longitudinal Data

When measurement is cross-sectional, individual differences in pubertal timing can be determined in several ways. First, individuals can be compared to published norms (e.g., Euling et al., 2008; Biro et al., 2013; Herman-Giddens et al., 2012). Second, researchers have often chosen to trichotomize individuals in a sample. In this case, early, on-time, and late timing groups may be created using cutoffs that reflect the upper and lower 20-30\% of a sex-based sample or those more than one standard deviation from the mean in either direction (e.g., Copeland et al., 2010; Dubas et al., 1991; Ge, Conger, \& Elder, 2001; Zehr et al., 2007). Third, timing variables can be created by regressing chronological age on pubertal status (and saving the residuals) or by standardizing pubertal status ratings within a year of chronological age and sex, so that higher scores reflect greater pubertal development relative to same-age, same-sex peers (e.g., Carter, Silverman, \& Jaccard, 2013; Crockett, Carlo, Wolf, \& Hope, 2013; Dorn, Susman, \& Ponirakis, 2003; Mendle, Leve, Van Ryzin, \& Natsuaki, 2014; Rudolph, TroopGordon, Lambert, \& Natsuaki, 2014).

Implementing one of these analytic procedures for timing requires careful attention to the question under study as well as the available measures of puberty within the dataset. Our recommendation is to create pubertal timing variables via residuals or standardizing within age bands rather than trichotomizing or using norms. Trichotimizing can limit inferential analysis options to group comparisons (e.g., ANOVAs), reduce power, and be sample-specific. Likewise, published norms are not updated frequently, may not always have adequate populations of racially, ethnically, or socioeconomically diverse youth, and sometimes rely on a comparatively small segment of the population to determine what is "normal." 
When measurement is longitudinal, researchers can consider advanced growth curve analyses in addition to adapting the methods described above (i.e., Raudenbush \& Bryk, 2002; Ram \& Grimm, 2007). Growth curve models inherently assess pubertal timing within the model design. These models have had a notable impact on the field (e.g., Beltz et al., 2014; Castellanos-Ryan, Parent, Vitaro, Tremblay, \& Seguin, 2013; Huang, Biro, \& Dorn, 2009; Marceau, Ram, Houts, Grimm, \& Susman, 2011; Mendle, Harden, Brooks-Gunn, \& Graber, 2010, 2012; Negriff, Blankson, \& Trickett, 2015), but they must be applied with careful attention to conceptual interpretation. These analyses generally involve fitting mixed effects (i.e., group means and their variation across individuals) models to longitudinal measures of pubertal status separately for boys and girls, and then extracting parameters from the curves that represent pubertal timing (or tempo; see below).

Depending on the functional form of the growth curve (e.g., linear, quadratic, logistic) and analytic choices of the researcher, pubertal timing can be reflected by the intercept (e.g., age at the onset of puberty or level of development at a certain age) or by interpolating the age at midpuberty (e.g., Tanner Stage 3); these pubertal timing estimates can then be related to behavior in subsequent analyses. Linear growth curves consider pubertal development to be steadily increasing across adolescence (e.g., Castellanos-Ryan et al., 2013; Mendle et al., 2010). Quadratic curves model pubertal development in a U- (or inverted U-) shape (Negriff et al., 2015), and logistic curves model pubertal development in an S-shape, with no change in childhood, a sharp increase in adolescence, and a leveling-out in adulthood (e.g., Huang et al., 2009; Marceau et al., 2011). Empirical results show that complex curves typically fit longitudinal puberty data better than linear ones (Marceau et al., 2011; Negriff et al., 2015), but that the curves provide similar estimates of pubertal timing and links to behavior (Beltz et al., 2014). Pubertal Tempo

Pubertal tempo is a measure of how quickly a youth develops. Some youth mature relatively quickly while others have a slower, more gradual maturation process. Converging evidence of the developmental significance of pubertal tempo is still mounting (Berenbaum et al., 2015). Because tempo indexes change over time, studies of pubertal tempo necessarily require more than one time point of data; optimally, researchers will have three or more assessments of puberty. 
Like timing, tempo estimates can be extracted from growth curve models, with tempo reflected in the rate of change, or slope, of the curves. Unlike pubertal timing, the meaning of tempo estimates is highly dependent upon the functional form of the trajectory over time; that is, whether it is a linear, quadratic, or logistic model (Beltz et al., 2014). For example, linear models have the same slope across time, so tempo reflects a constant rate of pubertal change. Quadratic and logistic models have curves, and in these models, slope is typically calculated where the curve changes direction (i.e., the inflection point), so tempo reflects instantaneous change, or change in the rate of change (Beltz et al., 2014; Marceau et al., 2011; Negriff et al., 2015). It is likely not surprising that pubertal tempo estimates from different models are not consistently related to each other, even in the same sample; for instance, tempo estimates from linear models were correlated .03 and .15 with estimates from logistic models in two samples of adolescent girls, with neither estimate consistently relating to behavior (Beltz et al., 2014).

This disconnect between pubertal tempo operationalizations highlights the importance of aligning theory and statistical methods when studying puberty. When making modeling decisions, it is beneficial to consider study questions and data, and remember that growth curve models can be sensitive to the timing, frequency, and spacing of measurements. For instance, a linear curve can be used if a researcher only has three measurements assessed in the midst of puberty, as more complex curves require more than three measurements. Alternatively, a logistic curve (or censored data set) should be used if the measurements do not completely capture puberty; studies that begin too late or end too early can miss the development of early maturing girls and late maturing boys, respectively. Thus, it is beneficial to consider both timing and tempo in models whenever possible.

Finally, although there is no consensus as to how many time points are necessary to estimate tempo, three or more assessments is optimal. It is true that within endocrinology research, tempo has occasionally been assessed as a simple difference score of the time it takes a girl to go from pubertal onset to menarche (e.g., Martí-Henneberg \& Vizmanos, 1997). It should be noted, however, that tempo can only be gauged from two time points when assessments span the entirety of puberty, from onset to completion, for every participant. Although it might be temptingly simple to subtract participants' level of development at Time 1 from their level of development at Time 2, this sort of difference score would be uninformative about pubertal tempo if the assessments captured only a segment of the pubertal process, as is the case in the 
majority of psychological studies. In these circumstances, a high difference score would simply reflect participants who experience more pubertal change during the study period and a lower difference score would reflect participants experiencing less pubertal change at the particular time the study was conducted. To illustrate, a person with a low difference score may have already experienced an unusually rapid tempo, and completed puberty prior to these assessments, or alternatively may not have yet begun maturing. Although even studies that include multiple time points of data may not fully capture the entirety of the pubertal process, nonlinear growth curve models, although complex, are currently the best methodological technique available for studying pubertal tempo.

Pubertal Synchrony

Synchrony is the extent to which different pubertal processes or features develop in concert (Marshall \& Tanner, 1969, 1970). For instance, puberty in girls typically begins with a growth spurt in height, followed by breast budding, axillary and pubic hair growth, and ends with menarche, but the initiation of these events and the extent to which they overlap with each other varies across individuals (Marshall \& Tanner, 1969). Although research in pubertal synchrony has been limited, there has been some consideration of the correspondence between adrenal and gonadal indicators of development (Corley, Beltz, Wadsworth, \& Berenbaum, 2015; Susman et al., 2010). Most notably, Thompson, Hammen, \& Brennan (2016) reported that asynchronous pubertal development in girls was associated more strongly with depression in late adolescence. Synchrony will be an important avenue for future work, especially because researchers often collapse across different puberty indicators, and the optimal statistical approaches for comparing and contrasting across indicators are still unclear. It is true that reliability of measurement generally increases with multiple indicators. However, this general rule of psychometrics only applies if measures assess the same construct, and may not hold for aspects of puberty that have different developmental courses or are driven by different hormonal processes (i.e., adrenal versus gonadal). Future investigations of synchrony not only have the potential to increase understanding of the significance of coinciding pubertal events, but may also challenge researchers to think deeply and precisely about the aspects of puberty that matter most for developing youth for the construct under study.

\section{Addressing Diversity and Social Context}


The timing of puberty varies according to race, ethnicity, biological sex, socioeconomic status, and social history (e.g., Biro et al., 2011; Ellis, 2004). It is likely that the accompanying psychological changes associated with puberty are saliently influenced by these identities and backgrounds as well. Unfortunately, some populations within these groups have been understudied in the puberty literature to date, making it difficult to gain a full understanding of puberty's impact on various psychosocial outcomes. Particularly under-represented are the experiences of racially and ethnically diverse youth, low-income youth, and lesbian, gay, bisexual, and transgendered (LGBT) youth (see also XX, this issue, blinded for review). From a puberty-specific perspective, it is worth noting that what it means to mature and to become an adult may differ based on personal background or social identity. In addition, early pubertal timing is disproportionately more common in African American and Latino youth (e.g., HermanGiddens et al., 2012), youth from lower socioeconomic contexts (James-Todd, Tehranifer, RichEdwards, Titievsky, \& Terry, 2010), or youth with histories of early life adversities (e.g., Mendle, Leve, Van Ryzin, Natsuaki, \& Ge, 2011). For developmental science that adequately and appropriately represents the experiences of a broad array of adolescents, considering these differences when selecting instruments, constructing hypotheses, and identifying key mediators and moderators of psychological experiences will enhance research quality and generalizability.

This lack of inclusion of diversity and social context in research on puberty likely has many origins. These may include a shortage of theoretical explanations for these populations; small numbers of researchers studying these issues; challenges in recruiting and retaining significant numbers of participants in these groups; and the added expense of effectively recruiting and retaining vulnerable populations. In this section, we highlight the challenges of addressing diversity and social context in research and discuss methodological strategies and considerations when studying racially and ethnically diverse youth, low-income youth, and LGBT youth during the pubertal transition.

Challenges in Addressing Diversity and Social Context

Effective research is an implicit social contract between a researcher and a participant, with participants sharing details of their minds, lives and personal histories, and researchers providing compensation, respect, and interpretation of their participant's lived experiences. The challenges of addressing diversity and social context in puberty research fall on both sides of this contract. On the one hand, many researchers lack experience or expertise in working with 
racially and ethnically diverse youth, low-income youth, and LGBT youth. As a result, they may be wary of delving into work within these populations and fearful of misrepresenting their participants' experiences. Researchers may also not have the expertise to recruit in areas where they might find more diverse samples, or these populations may not be found in the institutions or communities where researchers are easily able to recruit. On the other hand, sometimes the challenge lies within the particular population of interest. For example, racially and ethnically diverse families may be less willing than European Americans to participate in developmental research because of mistrust of the university or of research (Freimuth et al., 2001) or awareness of historical abuses on the part of researchers in the name of science. Individuals from lowerincome backgrounds may have practical concerns that curtail participation, as they may be more likely to lack adequate transportation, may need childcare assistance, or may not have flexible work schedules. It may simply be logistically more difficult for them to participate in research, especially during regular business hours, without flexibility or accommodations on the part of researchers (Gross, Julion, Fogg, 2001).

An additional concern is that racially and ethnically diverse, low-income, and LGBT populations may fear the ways in which researchers may portray their lives. Parents may be concerned about privacy, their children's readiness for a psychological project, or that research may reflect social biases or stigmatizing assumptions about their background. Parents are powerful in the research process: they play an active role in persuading or discouraging their children's participation, they provide consent; and they broker their children's assent.

Researchers may find it useful to meet with parents prior to and during the research process to gain their trust, to correct misconceptions, and to ameliorate any specific concerns that parents raise.

A particular conceptual consideration is recognizing that some youth from underrepresented backgrounds will experience both a different timing of puberty and have a different psychological experience, whereas other youth will not experience a different timing of puberty - but they will still have a different psychological experience. For example, from a strictly biological perspective, there is limited evidence that the physical maturation of sexual minority youth diverges substantially from that of other youth: LGBT youth experience the same set of hormonal and physical changes at the same time and in the same sequence as their non-LGBT peers. Yet the psychological experience of puberty seems to be meaningfully 
different (e.g., Grossman, Foss, \& D’Augelli, 2016; Savin-Williams, 2016). In particular, what it means to mature sexually, to experience sexual desire, to face a continually shifting set of social roles and expectations, and to integrate biological maturation with self-concept and self-esteem are intensified at puberty for LGBT youth (Savin-Williams, 2016). Because pubertal hormones strengthen feelings of sexual desire, puberty is often a time when boys and girls first become cognizant of same-sex attractions and consider their sexual orientation (Grossman et al., 2014). As puberty also marks a time when traditional gender roles and expectations become more entrenched (Hill \& Lynch, 1983), LGBT adolescents must also confront and redefine masculinity or femininity for themselves in a way that their peers do not. Thus, the psychological experiences of puberty among LGBT youth likely stem from individual-contextual interactions related to both puberty and to being a member of a stigmatized social group.

In contrast to the experiences of LGBT youth, racially and ethnically diverse youth, youth from lower socioeconomic backgrounds, or youth with histories of early life stressors experience different physical changes, in that they are more likely to have an earlier timing of puberty, and they are also likely to have different psychological experiences as well. For example, early pubertal timing is associated with greater depression in African American boys than African American girls (Hamlat, Stange, Alloy, \& Abramson, 2014), perhaps in part due to the specific stigmas, biases, and concerns that come with visibly resembling an adult African American male -- including concerns of physical safety, fairness in the legal system, or potentially being perceived as a threat by others. Likewise, girls with histories of childhood sexual assault are particularly likely to report depression during the pubertal transition, even when compared to peers who have experienced other forms of adversity (Mendle et al., 2014; Noll et al., 2017). Having powerlessly endured one premature sexual transition, the sexualized nature of earlier development may simply be more evocative or fraught for these girls.

Finally, it is worth noting that youth may also hold their own specific fears or attitudes about the research process (Nilsen \& Rogers, 2005). A particular recent concern among youth surrounds terminology. Specifically, how adolescents choose to self-identify may differ from how others perceive them or how researchers may find it expedient to categorize them. To illustrate, gender nonconforming (GN) youth are often referred to as "transgender," but this term may or may not be one that youth themselves adopt. Increasingly, adolescents are choosing to self-identify using terms designed to reflect a non-binary gender continuum - including 
genderqueer, gender fluid, or gender independent (Vance, Ehrensaft, \& Rosenthal, 2014) - but these terms are often not incorporated into questionnaire assessments. Sexual orientation identification may additionally be shaped by cultural values, gender roles, social class, religiosity, or language (e.g., Bridges, Selvidge, \& Matthews, 2003; Mays et al., 2004; Zea et al., 2003). For example, two spirit refers to Native American individuals who may engage in samegender sexual behavior or follow alternate gender roles (Adams \& Phillips, 2006) and down low is a term used to describe Latino and African American men who do not identify as gay, have sex with both men and women, and do not disclose their sexual behavior with men to female partners (Wolitski, Jones, Wasserman, \& Smith, 2006). An adolescent male who identifies as gay may not have the same understanding of his sexual orientation as an adolescent male who identifies as down low, but researchers may not be aware of the salient differences across these identities.

Methodological Strategies to Address Diversity and Social Context

Although the challenges associated with addressing diversity and social context are substantial, they are not insurmountable. We offer several strategies to mitigate these challenges. First, collaboration with researchers who have knowledge of the population under study is one way to improve understanding. These collaborators can help shape the research questions asked, the frameworks that are used to inform those questions, and the interpretation of results (Banks, 1998). Another option is to involve members of that community in the research process (also called community-based participatory research). Fostering healthy relationships between researchers and community members is a vital step toward remedying historical biases and mistrust of the university or of the research process.

Consulting with individuals from underrepresented backgrounds can also help to expand the depth and breadth of research topics in ways that are useful to those groups. As an example, Jean, Bondy, Wilkinson, and Forman (2009) conducted separate focus groups for fathers, mothers, and daughters aged 6 to 12 years to explore family beliefs and sociocultural dynamics surrounding puberty in Mexican American girls. Their findings suggest interventions addressing risk factors for early puberty, such as obesity, should focus on the entire family rather than on the individual child or the mother-daughter dyad. By eliciting information from fathers, mothers, and daughters, researchers gleaned new knowledge related to cultural and socioeconomic 
dynamics of puberty in this population and specific guidelines for interventions to address these dynamics.

A third strategy is to consider theoretical frameworks proposed for racially and ethnically diverse populations and to apply the utility of these explanations to understand groups of youth underrepresented in the puberty literature. The specific content of such frameworks might vary depending on the specific populations of focus. For example, the phenomenological variant of ecological systems theory (PVEST; Spencer, 2006; Spencer, Dupree, \& Hartmann, 1997) considers the impact of social inequalities (i.e., dealing with disseminated stereotypes related to body type and skin color, racial categorization and stereotypic definitions of physical attractiveness) and how these inequalities shape individual-context experiences. Central to this framework is the notion that emergent identities arise out of coping with stressors linked to social inequalities (Spencer, 2006). Puberty would be expected to play an important role in this process, as maturing into adulthood accentuates awareness of social roles, opportunities, and biases. Youth may assimilate salient puberty-related experiences into their existing self-concept and interpret these experiences in a manner that has the potential to cultivate a positive (or negative) view of themselves and their futures.

Finally, smaller methodological shifts may also be helpful. Researchers may want to increase their use of open-ended questions; conduct focus groups to determine preferred demographic terms; or allow participants to write-in demographic variables to avoid categorizations that may not be meaningful for participants. Recognizing that different dimensions of puberty may be differentially salient to particular cultures, they may also want to assess and to analyze multiple dimensions of puberty (i.e., menarche, voice changes, breast development). Additionally, research would benefit from considering within-group variation that goes beyond between-group comparisons. For example, Carter, Caldwell, Matusko, Antonucci, and Jackson (2010) demonstrated that African American girls, relative to Caribbean Black girls, appear to be less vulnerable to emotional distress during puberty, regardless of pubertal timing. Finally, once data are collected and analyses are completed, researchers may want to play close attention to the interpretation and dissemination of their results. In interpreting findings of research, it is important to consider the potential influences of racism, heterosexism, sexism, and other biases that may factor into how youth have responded to questionnaires, how results are presented, or how findings may be summarized within mainstream media outlets. 


\section{Discussion}

Puberty coincides with transformation across virtually every domain of life. The complexity of the transition itself is reflected in the intricacy needed to operationalize puberty for research purposes. Measurement of puberty must capture a dynamic, biologically-driven process. But it must also encompass an essential paradox: that puberty is both universal and individualized. Puberty is a transition that we all pass through on the way to adulthood, but there may be substantial variation in the timing and onset of key milestones, the pace at which the process unfolds, the correspondence of different pubertal indicators with each other; and the ways in which social identities might intersect with the psychological response to puberty.

Underlying discussions of the measurement of puberty is the overarching question of validity of measurement. The age and demographic background of participants, timing of assessments, operationalization of statistical parameters, and phrasing of survey questions may all influence accuracy, generalizability, and replicability of results. A particular consideration highlighted in this paper has been how different methodological and quantitative techniques can enable researchers to capture individual variation in a more valid way, whether that variation is in physical development itself (i.e., timing, tempo, or synchrony) or in the social contexts that shape psychological reactions to maturation. Data techniques that prioritize person-centered and person-specific analyses may be especially beneficial for allowing us to tap and to express the lived experiences of youth. Implicit in these techniques is the important reminder that even within particular groups or social contexts, we should expect variability in psychological reactions to maturation. We cannot assume that youth -- no matter their timing, tempo, synchrony, or contextual background - will necessarily respond to this transition in the same way.

It is also worth noting that measurement is only the foundation of good science and not a substitute for psychological theory. To move the field forward, we need to integrate methodological precision with an awareness that puberty is an essential human experience, which unfolds in the lives of real children in the real world. Youth are surrounded by people whom researchers will never meet, confronting a multitude of experiences that researchers cannot pragmatically assess. How can we capture the daily worlds of these children?

In recent years, as the literature has encouraged scholars to go "beyond pubertal timing," the challenge of maintaining theoretically driven research has become increasingly relevant. An 
over-reliance on puberty terminology - such as timing or tempo - runs the risk of abandoning the sort of perspective taking and psychological insight that characterizes the best theoretical science. We encourage scholars to think back to the core concept of puberty - which is change as they formulate hypotheses and interpret their data. To illustrate, pubertal tempo is salient not because it is relatively new to the literature, nor because it can be modeled in sophisticated ways. It is intriguing because it reflects broader recurrent questions about humans' psychological reaction to change, and whether sudden and rapid change is more difficult than gradual change. Likewise, pubertal timing echoes long-standing developmental questions about the correspondence between age and stage, mind and body, and normative versus specific experiences.

Conclusion

Youth today differ from past cohorts in the timing of pubertal onset, the duration of the transition, the social influences they encounter, and the demographic make-up and economic circumstances of the country in which they live. However, puberty as a topic of research will continue to inspire and to perplex developmentalists, for the simple reason that transitioning from childhood to adolescence is rich with personal, biological, and social significance. Incorporating the understudied aspects of puberty highlighted in this review, particularly with respect to diversity and context, is essential for enhancing the literature on puberty. Our hope is that this article both motivates and guides researchers as to tackle this pivotal developmental window.

\section{References}

Abbassi, V.(1998). Growth and normal puberty. Pediatrics, 102:507-511.

Adams, H., \& Phillips, L. (2006). Experiences of two-spirit lesbian and gay Native Americans: An argument for standpoint theory in identity research. Identity, 6, 273-291.

Aksglaede, L., Olsen, L. W., Sørensen, T. I., \& Juul, A. (2008). Forty years trends in timing of pubertal growth spurt in 157,000 Danish school children. PLoS One, 3(7), e2728. DOI: 10.1371/journal.pone.0002728

Aksglaede, L., Sørensen, K., Petersen, J. H., Skakkebæk, N. E., \& Juul, A. (2009). Recent decline in age at breast development: the Copenhagen Puberty Study. Pediatrics, 123(5), e932-e939. DOI: 10.1542/peds.2008-2491 
Albertsson-kWikland, K., Rosberg, S., Karlberg, J. \& Groth T. (1994). Analysis of 24-hour growth hormone profiles in healthy boys and girls of normal stature: Relation to puberty Journal of Clinical Endocrinology and Metabolism, 78(5):1195-201.

Banks, J. A. (1998). The lives and values of researchers: Implications for educating citizens in a multicultural society. Educational Researcher, 27, 4-17.

Beltz, A. M., \& Berenbaum, S. A. (2013). Cognitive effects of variations in pubertal timing: Is puberty a period of brain organization for human sex-typed cognition? Hormones and Behavior, 63(5), 823-828. doi:10.1016/j.yhbeh.2013.04.002

Beltz, A. M., Corley, R. P., Bricker, J. B., Wadsworth, S. J., \& Berenbaum, S. A. (2014). Modeling pubertal timing and tempo and examining links to behavior problems. Developmental Psychology, 50(12), 2715-2726. doi:10.1037/a0038096

Berenbaum, S. A., Beltz, A. M., \& Corley, R. (2015). The importance of puberty for adolescent development: Conceptualization and measurement Advances in Child Development and Behavior (Vol. 48, pp. 53-92).

Biro, F. M., Galvez, M. P., Greenspan, L. C., Succop, P. A., Vangeepuram, N., Pinney, S. M., ... Wolff, M. S. (2010). Pubertal assessment method and baseline characteristics in a mixed longitudinal study of girls. Pediatrics, 126(3), e583-e590. http://doi.org/10.1542/peds.2009-3079

Biro, F. M., Greenspan, L. C., Galvez, M. P., Pinney, S. M., Teitelbaum, S., Windham, G. C., ... \& Kushi, L. H. (2013). Onset of breast development in a longitudinal cohort. Pediatrics, 132(6), 1019-1027. doi:10.1542/peds.2012-3773

Bordini, B., \& Rosenfield, R. L. (2011). Normal pubertal development. Pediatrics in Review, 32(6), 223-229. DOI: 10.1542/pir.32-6-223

Bridges, S. K., Selvidge, M. M. D., \& Matthews, C. R. (2003). Lesbian women of color: Therapeutic issues and challenges. Journal of Multicultural Counseling and Development, 31, 113-130.

Brooks-Gunn, J., Petersen, A. C., \& Eichorn, D. (1985). The study of maturational timing effects in adolescence. Journal of Youth and Adolescence, 14(3), 149-161.

Byrne, M. L., Whittle, S., Vijayakumar, N., Dennison, M., Simmons, J. G., \& Allen, N. B. 
(2016). A systematic review of adrenarche as a sensitive period in neurobiological development and mental health. Developmental Cognitive Neuroscience. 10.1016/j.den.2016.12.004

Buckler, J.M., \& Wild, J. (1987). Longitudinal study of height and weight at adolescence. Archives of Diseases in Childhood, 62(12):1224-32.

Cabrera, S. M., Bright, G. M., Frane, J. W., Blethen, S. L., \& Lee, P. A. (2014). Age of thelarche and menarche in contemporary US females: a cross-sectional analysis. Journal of Pediatric Endocrinology and Metabolism, 27(1-2), 47-51.

Cance, J. D., Ennett, S. T., Morgan-Lopez, A. A., \& Foshee, V. A. (2012). The stability of perceived pubertal timing across adolescence. Journal of Youth and Adolescence, 41(6), 764-775. http://doi.org/10.1007/s10964-011-9720-0

Carter, R., Caldwell, C. H., Matusko, N., Antonucci, T. C., \& Jackson, J. S. (2011). Ethnicity, perceived pubertal timing, externalizing behaviors, and depressive symptoms among black adolescent girls. J Youth Adolesc, 40(10), 1394-1406. doi: 10.1007/s10964-010$9611-9$

Carter, R., Silverman, W. K., \& Jaccard, J. (2013). Race and perceived pubertal transition effects on girls' depressive symptoms and delinquent behaviors. Journal of Youth and Adolescence, 42(8), 1155-1168. doi:10.1007/s10964-012-9885-1

Carter, R., \& Williams, S. (2016). Self-perceptions of of pubertal timing and patterns of peer group activities and dating behavior among heterosexual adolescent girls. Journal of Adolescence, 47, 71-80. doi:10.1016/j.adolescence.2015.12.006

Casey V.A., Dwyer J.T., Coleman K.A., Krall E.A., Gardner J., Valadian I. (1991) Accuracy of recall by middle-aged participants in a longitudinal study of their body size and indices of maturation earlier in life. Annals of Human Biology, 8, 155-166.

Castellanos-Ryan, N., Parent, S., Vitaro, F., Tremblay, R. E., \& Seguin, J. R. (2013). Pubertal development, personality, and substance use: A 10-Year longitudinal study from childhood to adolescence. Journal of Abnormal Psychology, 122(3), 782-796. doi:10.1037/a0033133

Copeland, W., Shanahan, L., Miller, S., Costello, E. J., Angold, A., \& Maughan, B. (2010). Outcomes of early pubertal timing in young women: A prospective population-based 
study. American Journal of Psychiatry, 167(10), 1218-1225.

doi:10.1176/appi.ajp.2010.09081190

Corley, R. P., Beltz, A. M., Wadsworth, S. J., \& Berenbaum, S. A. (2015). Genetic influences on pubertal development and links to behavior problems. Behavior Genetics, 45(3), 294-312. doi:10.1007/s10519-015-9719-5

Crockett, L. J., Carlo, G., Wolff, J. M., \& Hope, M. (2013). The role of pubertal timing and temperamental vulnerability in adolescents' internalizing problems. Development and Psychopathology, 25, 377-389.

Deardorff, J., Hayward, C., Wilson, K. A., Bryson, S., Hammer, L. D., \& Agras, S. (2007). Puberty and gender interact to predict social anxiety symptoms in early adolescence. $\mathrm{J}$ Adolesc Health, 41(1), 102-104, doi:10.1016/j.jadohealth.2007.02.013.

Dorn, L. D., \& Biro, F. M. (2011). Puberty and its measurement: A decade in review. Journal of Research on Adolescence, 21(1), 180-195. doi:10.1111/j.1532-7795.2010.00722.x

Dorn, L. D., Dahl, R. E., Woodward, H. R., \& Biro, F. (2006). Defining the boundaries of early adolescence: A user's guide to assessing pubertal status and pubertal timing in research with adolescents. Applied Developmental Science, 10(1), 30 - 56. doi:dx.doi.org/10.1207/s1532480xads1001_3

Dorn, L. D., Susman, E. J., \& Ponirakis, A. (2003). Pubertal timing and adolescent adjustment and behavior: Conclusions vary by rater. Journal of Youth and Adolescence, 32(3), 157167. doi:10.1023/a:1022590818839

Dubas, J. S., Graber, J. A., \& Petersen, A. C. (1991). A longitudinal investigation of adolescents' chaning perceptions of pubertal timing. Developmental Psychology, 27(4), 580-586. doi:10.1037/0012-1649.27.4.580

Euling, S. Y., Herman-Giddens, M.E., Lee, P. A., Selevan, S.G., Juul, A. \& … Swan S. H. (2008).

Examination of US puberty-timing data from 1940 to 1994 for secular trends: pane1

findings. Pediatrics 121 (supp1 3), S172-S191.

Ellis B.J. (2004). Timing of pubertal maturation in girls: An integrated life history approach.

Psychological Bulletin,130, 920-958. 
Freimuth, V. S., Quinn, S. C., Thomas, S. B., Cole, G., Zook, E., \& Duncan, T. (2001).African Americans' views on research and the Tuskegee Syphilis Study. Social Science \& Medicine, 52(5), 797-808.

Ge, X. J., Conger, R. D., \& Elder, G. H. (2001). Pubertal transition, stressful life events, and the emergence of gender differences in adolescent depressive symptoms. Developmental Psychology, 37(3), 404-417. doi:10.1037//0012-1649.37.3.404

Goddings, A.-L., Beltz, A., Peper, J. S., Crone, E. A., \& Braams, B. R. (this volume). Structural and functional brain changes associated with puberty.

Graber, J. A. (2013). Pubertal timing and the development of psychopathology in adolescence and beyond. Hormones and Behavior, 64(2), 262-269. doi:10.1016/j.yhbeh.2013.04.003

Graber, J. A., Lewinsohn, P. M., Seeley, J. R., \& BrooksGunn, J. (1997). Is psychopathology associated with the timing of pubertal development? Journal of the American Academy of Child and Adolescent Psychiatry, 36(12), 1768-1776. doi:10.1097/00004583-19971200000026

Graber, J.A., Seeley, J.R., Brooks-Gunn, J., \& Lewinsohn, P.M. (2004). Is pubertal timing associated with psychopathology in young adulthood? Journal of the American Academy of Child and Adolescent Psychiatry,43, 718-726.

Gross, D., Julion, W., \& Fogg, L. (2001). What motivates participation and dropout among lowincome urban families of color in a prevention intervention? Family Relations, 50, 246254.

Hamlat, E. J., Stange, J. P., Alloy, L. B., \& Abramson, L. Y. (2014). Early pubertal timing as a vulnerability to depression symptoms: differential effects of race and sex. Journal of Abnormal Child Psychology, 42(4), 527-538. http://doi.org/10.1007/s10802-013-9798-9

Harden, K.P., Kretsch, N., Moore, S.R., \& Mendle, J. (2014). Hormonal influences on risk for disordered eating during puberty and adolescence. International Journal of Eating Disorders, Special Issue: Developmental Risk for Eating Disorders Across the Lifespan, 47,718-726. DOI: $10.1002 /$ eat.22317

Herman-Giddens, M. E., Steffes, J., Harris, D., Slora, E., Hussey, M., Dowshen, S. A., . . Reiter, E. O. (2012). Secondary sexual characteristics in boys: data from the pediatric research in office settings network. Pediatrics, 130(5), e1058-e1068. doi:

10.1542/peds.2011-3291

This article is protected by copyright. All rights reserved 
Herting, M. M., \& Sowell, E. R. (2017). Puberty and structural brain development in humans. Frontiers in Neuroendocrinology, 44, 122-137. doi:10.1016/j.yfrne.2016.12.003

Huang, B., Biro, F. M., \& Dorn, L. D. (2009). Determination of relative timing of pubertal maturation through ordinal logistic modeling: Evaluation of growth and timing parameters. Journal of Adolescent Health, 45(4), 383-388.

doi:10.1016/j.jadohealth.2009.02.013

Huang, B., Hillman, J., Biro, F. M., Ding, L., Dorn, L. D., \& Susman, E. J. (2012).

Correspondence between gonadal steroid hormone concentrations and secondary sexual characteristics assessed by clinicians, adolescents, and parents. Journal of Research on Adolescence, 22(2), 381-391. http://doi.org/10.1111/j.1532-7795.2011.00773.x

James-Todd, T., Tehranifar, P., Rich-Edwards, J., Titievsky, L., \& Terry, M. B. (2010). The impact of socioeconomic status across early life on age at menarche among a racially diverse population of girls. Annals of Epidemiology, 20(11), 836-842. doi:

10.1016/j.annepidem.2010.08.006

Jean, R. T., Bondy, M. L., Wilkinson, A. V., \& Forman, M. R. (2009). Pubertal development in Mexican American girls: the family's perspective. Qualitative Health Research, 19(9), 1210-1222, doi: 10.1177/1049732309344326

Korth-Schutz, S., Levin, L.D., \& New, M.I. (1976). Serum androgens in normal prepubertal and pubertal children and in children with precocious adrenarche. Journal of Clinical Endocrinology and Metabolism, 42(1):117-124.

Lee, Y., \& Styne, D. (2013). Influences on the onset and tempo of puberty in human beings and implications for adolescent psychological development. Hormones and behavior, 64(2), 250-261. https://doi.org/10.1016/j.yhbeh.2013.03.014

Marceau, K., Ram, N., Houts, R. M., Grimm, K. J., \& Susman, E. J. (2011). Individual differences in boys' and girls' timing and tempo of puberty: Modeling development with nonlinear growth models. Developmental Psychology, 47(5), 1389-1409. doi:10.1037/a0023838

Marshall, W.A., \& Tanner, J. M. (1969). Variations in pattern of pubertal changes in girls. Archives of Disease in Childhood, 44(235), 291-\&. doi:10.1136/adc.44.235.291

Marshall, W. A., \& Tanner, J. M. (1970). Variations in the pattern of pubertal changes in boys. Archives of Disease in Childhood, 45(13), 13-23. doi:10.1136/adc.45.239.13 
Martí-Henneberg, C., \& Vizmanos, B. (1997). The duration of puberty in girls is related to the timing of its onset. Journal of Pediatrics, 131(4), 618-621. doi:10.1016/s00223476(97)70073-8

Mays, V. M., Cochran, S. D., \& Zamudio, A. (2004). HIV prevention research: Are we meeting the needs of African American men who have sex with men? Journal of Black Psychology, 30, 78-105.

Mendle, J. (2014). Beyond pubertal timing: New directions for studying individual differences in development. Current Directions in Psychological Science, 23(3), 215-219. doi:10.1177/0963721414530144

Mendle, J., Harden, K. P., Brooks-Gunn, J., \& Graber, J. A. (2010). Development's tortoise and hare: Pubertal timing, pubertal tempo, and depressive symptoms in boys and girls. Developmental Psychology, 46(5), 1341-1353. doi:10.1037/a0020205

Mendle, J., Harden, K.P., Brooks-Gunn, J., \& Graber, J. (2012). Peer relationships and depressive symptomatology in boys at puberty. Developmental Psychology, 48, 429-435. doi: $10.1037 / \mathrm{a} 0026425$

Mendle, J., Leve, L. D., Van Ryzin, M., Natsuaki, M. N., \& Ge, X. (2011). Associations between early life stress, child maltreatment, and pubertal development among girls in foster care. Journal of Research on Adolescence, 21(4), 871-880. doi: 10.1111/j.15327795.2011.00746.x

Mendle, J., Ryan, R.M., McKone, K.M. (2016). Early childhood maltreatment and pubertal development: replication in a population-based sample. Journal of Research on Adolescence, 26, 595- 602. doi: 10.1111/jora.12201

Moore, S.R., Harden, K.P., \& Mendle, J. (2014). Pubertal timing and adolescent sexual behavior in girls. Developmental Psychology, 50, 1734-1745. doi: 10.1037/a0036027

Moore, S.R., McKone, K.M., \& Mendle, J. (2016). Recollections of puberty and disordered eating in young women. Journal of Adolescence, 53, 180-188. doi.org/10.1016/j.adolescence.2016.10.011

Mustanski, B. S., Garofalo, R., \& Emerson, E. M. (2010). Mental health disorders, psychological distress, and suicidality in a diverse sample of lesbian, gay, bisexual, and transgender youths. American journal of public health, 100(12), 2426-2432. 
Natsuaki, M. N., Samuels, D. V., \& Leve, L. D. (2014). Puberty, identity, and context: A biopsychosocial perspective on internalizing psychopathology in early adolescent girls. The Oxford handbook of identity development, 389-405.

Negriff, S., Blankson, A. N., \& Trickett, P. K. (2015). Pubertal timing and tempo: Associations with childhood maltreatment. Journal of Research on Adolescence, 25(2), 201-213. doi:10.1111/jora.12128

Negriff, S., \& Susman, E. J. (2011). Pubertal timing, depression, and externalizing problems: A framework, review, and examination of gender differences. Journal of Research on Adolescence, 21(3), 717-746. doi:10.1111/j.1532-7795.2010.00708.x

Nilsen, R. and Rogers, B. 2005. 'That's not a good idea, mom': Negotiating children's subjectivity while constructing 'home' as a research site. Children's Geographies, 3(3): 345-362. doi: 10.1080/14733280500353100

Noll, J. G., Trickett, P. K., Long, J. D., Negriff, S., Susman, E. J., Shalev, I., ... \& Putnam, F. W. (2017). Childhood sexual abuse and early timing of puberty. Journal of Adolescent Health, 60(1), 65-71. doi: 10.1016/j.jadohealth.2016.09.008

Petersen, A. C., Crockett, L., Richards, M., \& Boxer, A. (1988). A self-report measure of pubertal status: Reliability, validity, and initial norms. Journal of Youth and Adolescence, 17(2), 117-133. doi:10.1007/bf01537962

Petersen, A. C., Tobin-Richards, M., \& Boxer, A. (1983). Puberty: its measurement and its meaning. The Journal of Early Adolescence, 3(1-2), 47-62.

Raudenbush, S. W., \& Bryk, A. S. (2002). Hierarchical linear models: Applications and data analysis methods (2nd ed.) Thousand Oaks, CA: Sage.

Ram, N., \& Grimm, K. (2007). Using simple and complex growth models to articulate developmental change: Matching theory to method. International Journal of Behavioral Development, 31(4) 303-316.

Rey, R. A., Campo, S. M., Ropelato, M. G., \& Bergadá, I. (2016). Hormonal changes in childhood and puberty. In P. Kumanov \& A. Agarwal (Eds.), Puberty: Physiology and Abnormalities (pp. 23-37). Switzerland: Springer International Publishing.

Rudolph, K. D., Troop-Gordon, W., Lambert, S. F., \& Natsuaki, M. N. (2014). Long-term consequences of pubertal timing for youth depression: Identifying personal and 
contextual pathways of risk. Development and Psychopathology, 26(4), 1423-1444. doi:10.1017/s0954579414001126

Ryan, R. M., Mendle, J., \& Markowitz, A. J. (2015). Early childhood maltreatment and girls' sexual behavior: the mediating role of pubertal timing. Journal of Adolescent Health, 57(3),342-347. doi: 10.1016/j.jadohealth.2015.06.005

Savin-Williams, R. C. (2016). Becoming who I am: young men on being gay. Cambridge, MA: Harvard University Press.

Shirtcliff, E. A., Dahl, R. E., \& Pollak, S. D. (2009). Pubertal Development: Correspondence between hormonal and physical development. Child Development, 80(2), 327-337. http://doi.org/10.1111/j.1467-8624.2009.01263.x

Simmons, R. G., \& Blyth, D. A. (1987). Moving into adolescence: The impact of pubertal change and school context. New York: Aldine de Gruyter.

Sizonenko, P.D, \& Paunier, L. (1975). Hormonal changes in puberty III: Correlation of plasma bone age in normal boys and girls and in patients with Addison's disease or hypogonadism or with premature or late adrenarch. Journal of Clinical Endocrinology and Metabolism, 41(5): 894-904.

Spencer, M. B. (2006). Phenomenology and ecological systems theory: Development of diverse groups. Handbook of child psychology.

Spencer, M. B., Dupree, D., \& Hartmann, T. (1997). A phenomenological variant of ecological systems theory (PVEST): A self-organization perspective in context. Development and psychopathology, 9(04), 817-833.

Styne, D.M. \& Grumbach, M.M. (2016). Physiology and Disorders of Puberty. In S. Melmed, K.S. Polonsky, P.R. Larsen, and H.M. Kronenberg (Eds). In Williams Textbook of Endocrinology, 13th ed., pp. 1074-1218. Philadelphia: Elsevier.

Susman, E. J., \& Dorn, L. D. (2009). Puberty Handbook of Adolescent Psychology: John Wiley $\&$ Sons, Inc.

Susman, E. J., Houts, R. M., Steinberg, L., Belsky, J., Cauffman, E., DeHart, G., . . Eunice Kennedy Shriver, N. E. (2010). Longitudinal development of secondary sexual characteristics in girls and boys between ages $91 / 2$ and $151 / 2$ years. Archives of Pediatrics \& Adolescent Medicine, 164(2), 166-173. doi:doi:10.1001/archpediatrics.2009.261. 
Susman, E.J,, Nottelmann, E.D., Inoff-Germain, G.E,, Dorn, L.D., Cutler, G.B. ... \& Chrousos, G.P. (1985). The relation of relative hormonal levels and physical development and social-emotional behavior in young adolescents. Journal of Youth and Adolescence, 14, 245-264. doi: 10.1007/BF02090322.

Tanner, J.M. (1962). Growth at adolescence ( $2^{\text {nd }}$ edition). New York: Lippincott.

Thompson, S. M., Hammen, C., \& Brennan, P. A. (2016). The impact of asynchronous pubertal development on depressive symptoms in adolescence and emerging adulthood among females. Journal of Youth and Adolescence, 45(3), 494-504. doi: 10.1007/s10964-0150402-1

Veldhuis, J.D., Roemmich, J.N., \& Rogoo, A. D., Gender and sexual maturation-dependent contrasts $\mathrm{n}$ the neuroregulation of growth hormone secretion in prepubertal an late adolescent males and females: a general clinical research center-based study. Journal of Clinical Endocrinology and Metabolism, 85:2385-94

Wolitski, R. J., Jones, K. T., Wasserman, J. L., \& Smith, J. C. (2006). Self-identification as "down low" among men who have sex with men (MSM) from 12 US cities. AIDS and Behavior, 10, 519-529

Zea, M. C., Reisen, C. A., Poppen, P. J., Echeverry, J. J., \& Bianchi, F. T. (2004). Disclosure of HIV-positive status to Latino gay men's social networks. American Journal of Community Psychology, 33, 107-116.

Zehr, J. L., Culbert, K. M., Sisk, C. L., \& Kiump, K. L. (2007). An association of early puberty with disordered eating and anxiety in a population of undergraduate women and men. Hormones and Behavior, 52(4), 427-435. doi:10.1016/j.yhbeh.2007.06.005 